\title{
Aplicação de ácido salicílico em plantas de arroz submetidas a competição com arroz- vermelho
}

\author{
Alessandro Porto Fermiano ${ }^{1}$, Jessica Fernandes Kaseker ${ }^{1}$, Marcos André Nohatto ${ }^{1 *}$, Jadson \\ Daminelli de Oliveira ${ }^{1}$, Eliete de Fátima Ferreira da Rosa ${ }^{1}$, Daiane Heloisa Nunes ${ }^{1}$
}

\begin{abstract}
RESUMO: O uso de ácido salicílico, no tratamento de sementes ou aplicação foliar, tem sido avaliado como estratégia promissora para incrementar a tolerância das culturas frente a estresses bióticos, abióticos e xenobióticos. Neste estudo, o objetivo foi avaliar o efeito do ácido salicílico em plantas de arroz submetidas ao estresse proveniente da competição com o arroz-vermelho. O experimento foi conduzido em casa de vegetação no ano agrícola 2014/2015. O delineamento experimental foi completamente casualizado, com quatro repetições. Os tratamentos foram dispostos em esquema fatorial, sendo composto por sementes de arroz embebidas em diferentes concentrações de ácido salicílico $(0,15,45$, 135 e 405 ppm); e, o fator B foram dois ambientes: sem e com competição do arroz-vermelho. As variáveis avaliadas foram número de afilhos, estatura e massa da matéria seca da parte aérea. A competição com o arroz-vermelho reduziu o número de afilhos, estatura e massa da matéria seca do arroz, sendo que o ácido salicílico, em geral, não foi suficientemente capaz de reverter o efeito negativo causado pela interferência com a daninha. No entanto, a utilização do ácido salicílico em plantas livres da competição com o arroz-vermelho, demonstrou ser alternativa promissora para melhorar o desempenho morfológico do arroz.
\end{abstract}

Palavras-chave: Oryza sativa, regulador de crescimento, interferência.

\section{Application of salicylic acid in rice plants submitted to competition with red rice}

\begin{abstract}
The use of salicylic acid, in the treatment of seeds or foliar application, has been a promising strategy to increase the tolerance of crops to biotic, abiotic and xenobiotic stresses. In this study, the objective was to evaluate the effect of salicylic acid on rice plants submitted to stress from competition with red rice. The experiment was conducted under greenhouse conditions in the agricultural year 2014/2015. The experimental design was completely randomized, with four replications. The treatments were arranged in a factorial scheme, consisting of rice seeds soaked in different concentrations of salicylic acid $(0,15,45,135$ and $405 \mathrm{ppm})$; and, factor B were two environments: without and with rice-red competition. The variables were number of tillers, height and shoot dry matter. The competition with red rice reduced the number of tillers, height and shoot dry matter of the rice; and salicylic acid, in general, was not enough able to reverse the negative effect caused by interference with the weed. However, the use of salicylic acid in competitionfree plants has been shown to be a promising alternative to improve the morphological performance of rice.
\end{abstract}

Keywords: Oryza sativa, growth regulator, interference.

\section{INTRODUÇÃO}

O arroz (Oryza sativa L.) está entre os cereais mais consumidos e produzidos no mundo, ocupando área de 159 milhões de hectares e produção de 740 milhões de toneladas (FOOD AND AGRICULTURE ORGANIZATION OF THE UNITED NATIONS - FAOSTAT, 2017). O Brasil é o $9^{\circ}$ maior produtor mundial, apresentando na safra 2016/17, área de 1,9 milhões de hectares com produção de 12,3 milhões de toneladas (COMPANHIA NACIONAL DE ABASTECIMENTO - CONAB, 2017), o que evidencia a baixa produtividade nacional $(6,2 \mathrm{t} / \mathrm{ha})$ quando comparada o potencial produtivo da cultura.

A produção do arroz pode ser afetada por diversos fatores, destacando-se o prejuízo causado pelas plantas daninhas, especialmente pelo arrozvermelho, considerada a principal no arroz irrigado.
Essa daninha apresenta normalmente a maior estatura, área foliar, massa da matéria seca da parte aérea (LAGO, 2008), maior eficiência na utilização de $\mathrm{CO}_{2}$ (ZISKA; McCLUNG, 2008) e nitrogênio (CHAUHAN; JOHNSON, 2011). Além disso, apresenta degrane mais precoce das espiguetas e maior dormência das sementes, o que propicia o reabastecimento do banco de sementes do solo, perpetuando a infestação nas áreas orizícolas (NOLDIN et al., 1999).

Para combater o estresse proveniente da competição, por exemplo, as plantas apresentam mecanismos que protegem as membranas celulares dos efeitos prejudiciais das espécies reativas de oxigênio (EROs) (SCANDALIOS, 2005). Esses mecanismos aumentam sua atividade mediante a utilização de determinados produtos químicos, tais 
como reguladores de crescimento, promovendo incremento na tolerância da planta contra o estresse (FAROOQ et al., 2009). Dentre esses produtos destaca-se o ácido salicílico (AS), capaz de reduzir os efeitos negativos nas culturas frente a estresses bióticos, como patógenos (SILVA et al., 2016), plantas parasitas (YANG et al., 2016) e insetos (RODRÍGUEZ-ÁLVAREZ et al., 2015); abióticos, como metais pesados (WAEL et al., 2015), salinidade (GUNES et al., 2007), deficiência hídrica (LATIF et al., 2016), temperatura e radiação UV-B (MARTEL; QADERI, 2016); e xenobióticos, como a utilização de herbicidas (DIAS et al., 2017).

Hipotetiza-se que a utilização do AS também aumenta a capacidade competitiva das plantas de arroz, contribuindo para atenuar os efeitos negativos da competição e melhorar o potencial produtivo da cultura. No entanto, essa hipótese ainda não foi confirmada, sendo necessários estudos para avaliar a resposta desse composto na planta. Dessa forma, o objetivo desse trabalho é avaliar o efeito do ácido salicílico em plantas de arroz submetidas ao estresse proveniente da competição com o arroz-vermelho.

\section{MATERIAL E MÉTODOS}

O experimento foi conduzido em casa de vegetação na estação de cultivo 2014/2015. As unidades experimentais foram compostas por vasos plásticos com capacidade volumétrica de $6 \mathrm{~L}$, preenchidos com solo Gleissolo Melânico e adubação realizada conforme as recomendações para a cultura do arroz irrigado (SOCIEDADE SULBRASILEIRA DE ARROZ IRRIGADO - SOSBAI, 2010).

O delineamento experimental foi inteiramente casualizado, com quatro repetições, sendo instalado em esquema fatorial, onde o fator A foi composto por sementes de arroz (Epagri 108), embebidas em diferentes concentrações de ácido salicílico $\left(\mathrm{C}_{7} \mathrm{H}_{6} \mathrm{O}_{3} ; 138,12\right.$ g.mol $\left.{ }^{-1}\right)(0,15,45,135$ e 405 ppm) por 36 horas; e, o fator $\mathrm{B}$ foram dois ambientes: sem (duas plantas de arroz por unidade experimental) e com competição do arrozvermelho (duas plantas de arroz associadas com 20 plantas da daninha).

Aos 60 DAE (dias após a emergência) foram avaliadas as seguintes variáveis: estatura (EST) $\left(\mathrm{cm}\right.$ planta $\left.^{-1}\right)$, número de afilhos e massa da matéria seca da parte aérea (MMSPA) $\left(\mathrm{g}\right.$ planta $\left.^{-1}\right)$. A EST foi obtida pela medida da distância da base até a extremidade da última folha. O número de afilhos foi realizada com a contagem manualmente e visualmente, enquanto a MMSPA foi quantificada pela pesagem da parte aérea das plantas após serem secas em estufa a $60{ }^{\circ} \mathrm{C}$ por 96 horas.

Os dados obtidos foram analisados quanto à sua normalidade (teste de Shapiro Wilk) e, posteriormente, foram submetidos à análise de variância $(p \leq 0,05)$. No caso de ser constatada significância estatística, foi realizada a análise de regressão, ajustando-se os dados a equação polinomial quadrática, conforme segue (Equação 1):

$$
y=y 0+a x+b x^{2} \quad \text { (Equação 1) }
$$

Onde: $y=$ variável de interesse; $x=$ concentração do AS; e, $a, y 0$ e $b$ são parâmetros estimados da equação.

\section{RESULTADOS E DISCUSSÃO}

Houve interação entre as concentrações de ácido salicílico aplicadas e as plantas de arroz (com e sem competição) para todas as variáveis, sendo que os resultados dessas ajustarem-se à equação de regressão polinomial quadrática (Figuras 1, 2 e 3).

Observou-se, em geral, que a utilização do ácido salicílico incrementou o número de afilhos nas plantas de arroz livres da interferência causada pelo arroz-vermelho (Figura 1). O AS é regulador de crescimento capaz de incrementar o conteúdo de água, taxa fotossintética e condutância estomática (HABIBI, 2012), o que possivelmente favoreceu a emissão de novas estruturas vegetativas pela planta.

Já, sob competição com a daninha, o efeito do regulador foi menos evidente comparado ao anterior, mas observou-se suave aumento no número de afilhos até $135 \mathrm{ppm}$ (Figura 1). Estudos têm demonstrado que a capacidade do AS de aumentar a tolerância das culturas frente ao estresse tem sido associado ao aumento da síntese de prolina, fenóis e antocianinas que, por sua vez, protegem o maquinário fotossintético pela estabilização da estrutura da Rubisco (FAROOQ et al., 2009; NAZAR et al., 2015). Além disso, tanto as antocianinas como os fenóis têm anel aromático na sua estrutura, que atua como estabilizador da membrana durante o estresse (OLGA et al., 2003) e induz o processo de remoção das EROs nas células (TAKAHAMA; ONIKI, 1997). 


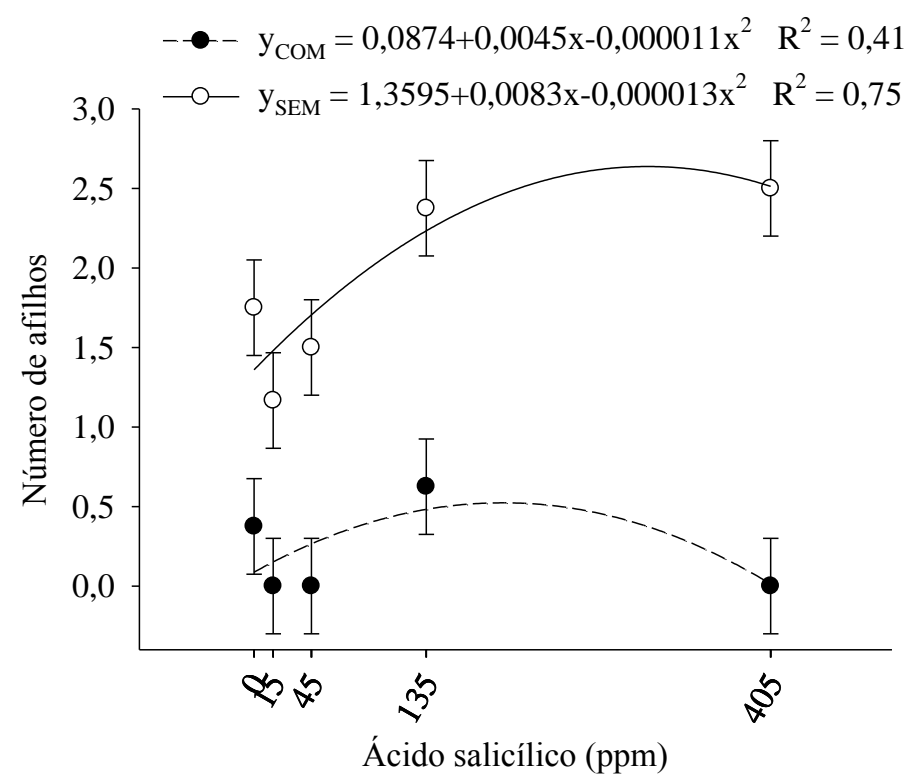

Figura 1. Número de afilhos em arroz com e sem competição com plantas de arroz-vermelho, submetidas a diferentes concentrações de ácido salicílico, avaliada aos 60 dias após a emergência. Os pontos constituem os valores médios das repetições; as barras representam os intervalos de confiança.

Ao avaliar a estatura, quando na ausência de competição, verifica-se elevação da variável com o aumento da dose do AS (Figura 2). Enquanto que para as plantas submetidas à interferência do arrozvermelho, observa-se pronunciado aumento da estatura até 135 ppm, seguido de redução da variável com 405 ppm, indicando toxicidade do AS em altas concentrações. Silveira et al. (2000), ao avaliar a parte aérea do arroz nas doses de 10 e $20 \mu \mathrm{M}$ AS (equivalente a 1381,21 e 2762,42 ppm), também verificaram efeito fitotóxico em altas concentrações de AS, corroborando com os resultados obtidos.
A explicação possivelmente está relacionada com a capacidade do AS atuar na regulação da biossíntese de lignina (GALLEGO-GIRALDO et al., 2011), resultando na rigidez da parede celular e, consequentemente, obstrução da elongação das células. Esse efeito prejudica a superfície de absorção de água e nutrientes, além da habilidade competitiva da cultura pelo recurso luz, quando considerado a redução da estatura, o que possivelmente foi potencializado sob condições de interferência com o arroz-vermelho.

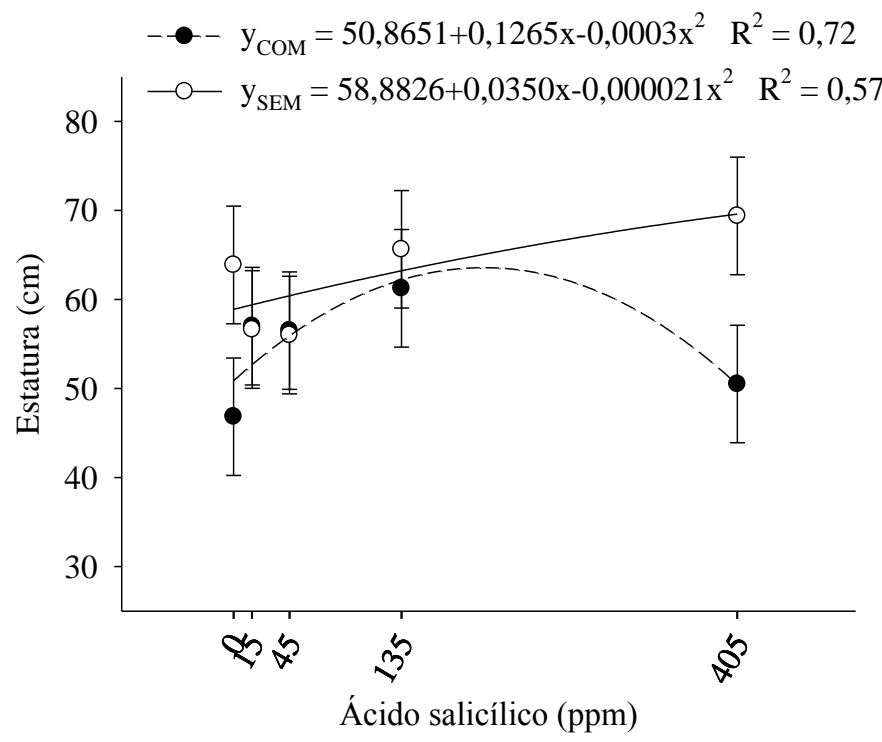

Figura 2. Estatura de plantas de arroz com e sem competição com plantas de arroz-vermelho, submetidas a diferentes concentrações de ácido salicílico, avaliada aos 60 dias após a emergência. Os pontos constituem os valores médios das repetições; as barras representam os intervalos de confiança. 
Com relação à MMSPA, semelhante ao comportamento observado para o número de afilhos e estatura, observou-se, em geral, aumento da variável na ausência de competição com a daninha com o incremento da dose do AS (Figura 3). Ao avaliar a utilização do AS, independentemente da forma de aplicação (tratamento de sementes e foliar), Farooq et al. (2009) verificaram aumento da MMSPA no arroz. Khodary (2004), também detectando aumento da MMSPA, mas na cultura do milho, atribui ao AS a função de aceleração do desempenho da fotossíntese e metabolismo dos carboidratos, o que ajudaria a explicar o aumento dos valores da variável MMSPA.

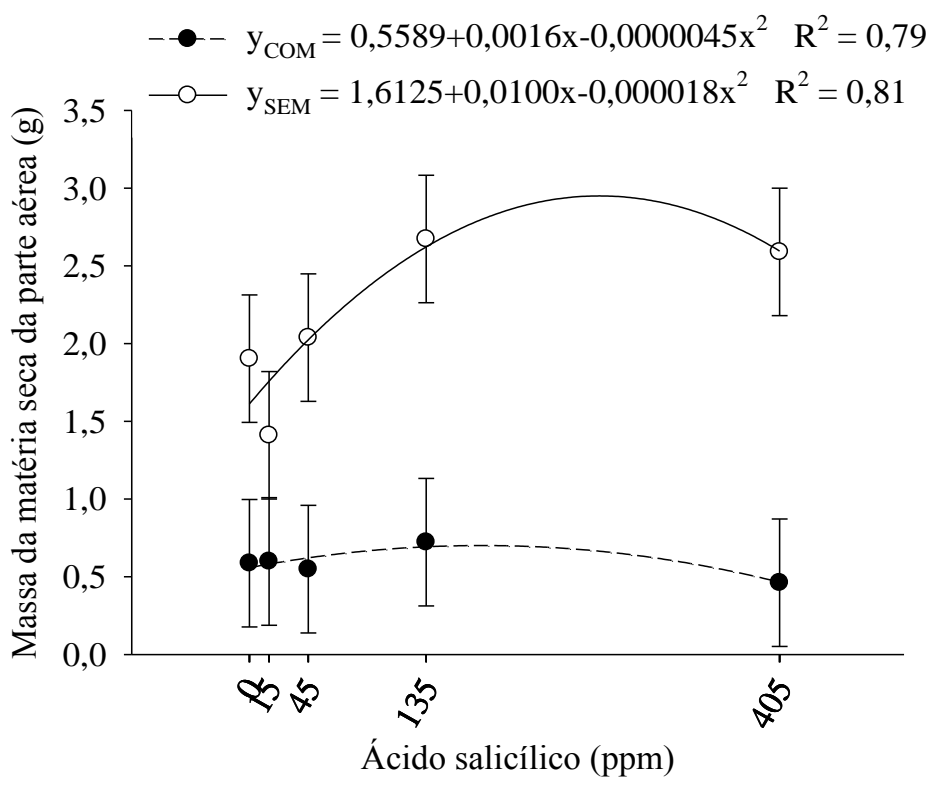

Figura 3. Massa da matéria seca da parte aérea de plantas de arroz com e sem competição com plantas de arroz-vermelho, submetidas a diferentes concentrações de ácido salicílico, avaliada aos 60 dias após a emergência. Os pontos constituem os valores médios das repetições; as barras representam os intervalos de confiança.

Em condições onde o arroz foi exposto a interferência com o arroz-vermelho, não se observou efeito pronunciado do AS na variável avaliada. Isso significa que as alterações nas outras variáveis (número de afilhos e estatura), especialmente na dose 135 ppm, não foram suficientemente capazes de afetar significativamente o comportamento da MMSPA quando a cultura é submetida à competição com a daninha.

Durães (2006), ao avaliar a resposta da aplicação de ácido salicílico no feijão (cultivar Aporé) submetido a estresse hídrico, também não obteve resposta significativa a MMSPA, demonstrando a insensibilidade ao tratamento com o regulador. Fatores como a concentração, espécie, condições de cultivo estão relacionados com a resposta positiva, negativa ou neutra sob o desenvolvimento da planta após utilização do AS (KERBAUY, 2008), o que instiga a realização de novos estudos.

\section{CONCLUSÃO}

1. A competição com o arroz-vermelho reduziu o número de afilhos, estatura e massa da matéria seca do arroz, sendo que o ácido salicílico, em geral, não foi suficientemente capaz de reverter o efeito negativo causado pela interferência com a daninha.

2. A utilização do ácido salicílico, no tratamento de sementes, em plantas livres da competição com o arroz-vermelho, demonstrou ser alternativa promissora para melhorar o desempenho morfológico do arroz.

\section{REFERÊNCIAS}

CHAUHAN, B. S.; JOHNSON, D. E. Competitive interactions between weedy rice and cultivated rice as a function of added nitrogen and the level of competition. Weed Biology and Management, Medford, v.11, n.4, p.202-209, 2011.

COMPANHIA NACIONAL DE ABASTECIMENTO CONAB. Acompanhamento da Safra Brasileira de Grãos. $2017 . \quad$ Disponível em: http://www.conab.gov.br/conteudos.php?a=1252. Acesso em: 24 Abril. 2017.

DIAS, R. C.; MELO, C. A. D.; SANTOS, L. P. D.; SILVA, G. S.; OLIVEIRA, G. D.; CARNEIRO, P.; REIS, M. R. Ácido salicílico como atenuador de fitotoxicidade causada pelo flumioxazin na cultura do trigo. Revista de Ciências Agrárias/Amazonian Journal of Agricultural 
and Environmental Sciences, Belém, v.60, n.2, p.152157, 2017.

DURÃES, M. A. B. Resposta de duas populações de feijões (Phaseolus vulgaris L.) tratadas com ácido salicílico e submetidas a estresse hídrico. 2010. 32f. Dissertação (Mestrado em Agronomia) - Universidade do Oeste Paulista, São Paulo.

FOOD AND AGRICULTURE ORGANIZATION OF THE UNITED NATIONS - FAOSTAT. Production of cereals and share in world. 2016. Disponível em: <http://faostat.fao.org/site/339/default.aspx>. Acesso em: 15 jan. 2017.

FAROOQ, M.; BASRA, S. M. A.; WAHID, A.; AHMAD, N.; SALEEM, B. A. Improving the drought tolerance in rice (Oryza sativa L.) by exogenous application of salicylic acid. Journal of Agronomy and Crop Science, Medford, v.195, n.4, p.237-246, 2009.

GALLEGO-GIRALDO, L.; ESCAMILLA-TREVINO, L.; JACKSON, L. A.; DIXON, R. A. Salicylic acid mediates the reduced growth of lignin own-regulated plants. Proceedings of the National Academy of Sciences of the United States of America, Washington, v.108, n.51, p.20814-20819, 2011.

GUNES, A.; INAL, A.; ALPASLAN, M.; ERASLAN, F.; BAGCI, E. G.; CICEK, N. Salicylic acid induced changes on some physiological parameters symptomatic for oxidative stress and mineral nutrition in maize (Zea mays L.) grown under salinity. Journal of Plant Physiology, East Melbourne, v.164, n.6, p.728-736, 2007.

HABIBI, G. Exogenous salicylic acid alleviates oxidative damage of barley plants under drought stress. Acta Biologica Szegediensis, Szeged, v.56, n.1, p.57-63, 2012.

KERBAUY, G. B. Fisiologia Vegetal. 2. ed. Rio de Janeiro: Guanabara Koogan, 2008. 431p.

KHODARY, S. E. A. Effect of salicylic acid on the growth, photosynthesis and carbohydrate metabolism in salt-stressed maize plants. International Journal of Agriculture and Biology, Faisalabad, v.6, n.1, p.5-8, 2004.

LAGO, I. Desenvolvimento do arroz e do arroz vermelho: Modelagem e resposta à mudança climática. 2008. 94f. Dissertação (Mestrado em Agronomia) Universidade Federal de Santa Maria, Rio Grande do Sul.

LATIF, F.; ULLAH, F.; MEHMOOD, S.; KHATTAK, A.; KHAN, A. U.; HUSAIN, I. Effects of salicylic acid on growth and accumulation of phenolics in Zea mays L. under drought stress. Acta Agriculturae Scandinavica, Stockholm, v.66, n.4, p.325-332, 2016.

MARTEL, A. B.; QADERI, M. M. Does salicylic acid mitigate the adverse effects of temperature and ultraviolet-B radiation on pea (Pisum sativum) plants?
Environmental and Experimental Botany, Elmsford, v.122, n.1, p.39-48, 2016.

NAZAR, R.; UMAR, S.; KHAN, N. A.; SAREER, O. Salicylic acid supplementation improves photosynthesis and growth in mustard through changes in proline accumulation and ethylene formation under drought stress. South African Journal of Botany, Pretoria, v.98, n.1, p.84-94, 2015.

NOLDIN, J. A.; CHANDLER, J. M.; McCAULEY, G. N. Red rice (Oryza sativa) biology. I. Caracterization of red rice ecotypes. Weed Technology, Washington, v.13, n.1, p.12-18, 1999.

OLGA, B.; EIJA, V.; KURT, V. F. Antioxidants, oxidative damage and oxygen deprivation stress: a review. Annals of Botany, London, v.91, n.1, p.179-194, 2003.

RODRÍGUEZ-ÁLVAREZ, C. I.; LÓPEZ-CLIMENT, M. F.; GÓMEZ-CADENAS, A.; KALOSHIAN, I.; NOMBELA, G. Salicylic acid is required for Mi-1mediated resistance of tomato to whitefly Bemisia tabaci, but not for basal defense to this insect pest. Bulletin of Entomological Research, Cambridge, v.105, n.5, p.574$582,2015$.

SCANDALIOS, J. G. Oxidative stress: molecular perception and transduction of signals triggering antioxidant gene defenses. Brazilian Journal of Medical and Biological Research, Ribeirão Preto, v.38, n.7, p.995-1014, 2005.

SILVA, M. S.; SILVA, R. P.; SOUZA, A. V. L.; XAVIER, Y. P. M.; OLIVEIRA, A. C.; COQUEIRO, D. S. O. Aplicação exógena do ácido salicílico em maracujazeiro-amarelo para o controle do vírus do endurecimento dos frutos. Arquivos do Instituto Biológico, São Paulo, v.83, n.1, p.1-7, 2016.

SILVEIRA, M. A. M.; MORAES, D. M.; LOPES, N. F. Germinação e alterações bioquímicas em sementes de arroz tratadas com ácido salicílico. Revista Brasileira de Sementes, Londrina, v.22, n.2, p. 200-205, 2000.

SOCIEDADE SUL-BRASILEIRA DE ARROZ IRRIGADO - SOSBAI. Arroz Irrigado: recomendações técnicas da pesquisa para o Sul do Brasil. Bento Gonçalves: SOSBAI, 2010. 188p.

TAKAHAMA, U.; ONIKI, T. A peroxide/phenolics/ascorbate system can scavenge hydrogen peroxide in plant cells. Physiologia Plantarum, Medford, v.101, n.4, p.845-852, 1997.

WAEL, M. S.; MOSTAFA, M. R.; TAIA, A. A., SAAD, M. H.; MAGDI, T. A. Alleviation of cadmium toxicity in common bean (Phaseolus vulgaris L.) plants by the exogenous application of salicylic acid. The Journal of Horticultural Science and Biotechnology, v.90, n.1, p.83-91, 2015. 
YANG, C.; HU, L. Y.; ALI, B.; ISLAM, F.; BAI, Q. J.;

YUN, X. P.; YONEYAMA, K.; ZHOU, W. J. Seed treatment with salicylic acid invokes defence mechanism of Helianthus annuus against Orobanche cumana. Annals of Applied Biology, Wellesbourne, v.169, n.3, p.408-422, 2016.

ZISKA, L.; McCLUNG, A. Differential response of cultivated and weedy (red) rice to recent and projected increases in atmospheric carbon dioxide. Agronomy Journal, Madison, v.100, n.5, p.1259-1263, 2008. 